\title{
Management of Opportunistic Infections after Organ Transplantation
}

\author{
Department of Surgery, Gangnam Severance Hospital, Yonsei University College of Medicine, Seoul, Korea
}

\author{
Im-kyung Kim, M.D. and Man Ki Ju, M.D.
}

\begin{abstract}
Solid organ transplantation is a therapeutic option for end-stage organ diseases. However, complications including infection and graft rejection, which are related to immunosuppressive therapy, remain the major causes of morbidity and mortality following solid organ transplantation. The optimal approach to infection in solid organ transplant recipients is prevention; failing this, prompt and aggressive diagnosis and therapy are essential. In addition, the epidemiology of infections after solid organ transplantation has shifted as a result of changes in immunosuppressive strategies and improved survival. Immunosuppression must be linked with appropriate vaccinations, donor and recipient screening, patient education regarding infectious risks and lifestyle, monitoring, and antimicrobial prophylaxis.
\end{abstract}

Key Words: Organ transplantation, Infection, Immunosuppression 중심 단어: 장기이식, 감염, 면역억제

\section{INTRODUCTION}

Solid organ transplantation is a therapeutic option for end-stage organ diseases. Liver, kidney, heart, and lung transplantations have become the standard therapy for selected end-stage diseases. However, complications such as infection and graft rejection, which are related to immunosuppressive therapy, remain the major causes of morbidity and mortality following solid organ transplantation.

The host response is also less effective because of the mismatch in major histocompatibility antigens between the organ donor and host, which reduces the efficacy of direct pathway antiviral cellular immune responses. These factors render the allograft susceptible to invasive viral infection.

There are 3 general timeframes during which different

Received February 24, 2015

Revised March 4, 2015

Accepted March 4, 2015

Corresponding author: Man Ki Ju

Department of Surgery, Gangnam Severance Hospital, 211 Eonju-ro, Gangnam-gu, Seoul 135-720, Korea

Tel: 82-2-2019-3893, Fax: 82-2-3462-5994

E-mail: mkju@yuhs.ac common pathogens cause infectious diseases.

Most infections occurring during the first month after transplantation are related to surgery and postoperative hospitalization, including surgical site, lung, urinary tract, and indwelling device infections, and they are similar to those occurring in general surgical patients. After the first month, opportunistic infections begin to appear because of immunosuppression and immunomodulating viral infections such as cytomegalovirus (CMV) infection. Beyond the six months after transplantation, most patients have good transplant outcome and receive minimal immunosuppression, suffer from infections similar to those of the general population. Patients requiring high immunosuppression owing to recurrent acute or chronic rejection remain at risk of opportunistic infections classically observed during the second to sixth month after transplantation. Moreover, some patients may experience chronic viral infections such as hepatitis $\mathrm{B}$ or $\mathrm{C}, \mathrm{CMV}$, Epstein-Barr virus, or $\mathrm{BK}$ virus infection.

The optimal approach to infection in solid organ transplant recipients is prevention; failing this, its prompt and aggressive diagnosis and therapy are essential. 


\section{BACTERIAL INFECTION}

\section{Clostridium difficile}

Clostridium difficile is known to produce protein endotoxins that cause colonic mucosal inflammation and injury. This infection may present as diversely as fever, abdominal pain, and diarrhea. Antimicrobial therapy is a well-known risk factor for $C$. difficile infection.

In a retrospective study of 1932 kidney and kidney-pancreas transplantation patients, the overall incidence of $C$. difficile colitis was $8 \%$, compared to $1 \sim 4 \%$ in the general surgery population(1).

In out setting, immunosuppression itself does not appear to increase $C$. difficile infection in kidney transplant patients(2).

Metronidazole 250 500 mg orally 3 4 times daily for $10 \sim 14$ days is considered the treatment of choice. If patients fail to respond to metronidazole, vancomycin $125 \mathrm{mg}$ orally 4 times daily for 10 14 days may be useful. Concerns about increased vancomycin resistance in other pathogens, such as enterococci, further discourage the use of oral vancomycin as the first-line therapy for $C$. difficile infection.

\section{Mycobacterium tuberculosis}

Latent tuberculosis (TB) infection can be reactivated because of immunosuppression. The infection may also be acquired from donors. Most transplant centers screen for TB infection preoperatively $(3,4)$.

Treatmentof TB infection is not simple, particularly when combined with immunosuppressive therapy. Drug interactions create unique challenges, for example, cyclosporine, sirolimus, and tacrolimus are all substrates of cytochrome p450-3A isoenzymes, and a significant dose increase of these immunosuppressive agents may be necessary to maintain the therapeutic drug concentrations in the presence of rifampin $(5,6)$.

\section{VIRAL INFECTION}

\section{Cytomegalovirus (CMV)}

Human cytomegalovirus or human herpesvirus 5 (CMV) belongs to the order Herpesvirales, family Herpesviridae, subfamily Betaherpesvirinae, genus Cytomegalovirus, and species Human herpesvirus 5(7). Symptomatic CMV infection occurs in 20 60\% of all transplant recipients and is a significant cause of increased morbidity and mortality in this population $(8,9)$. Compared with other organ transplant recipients, renal transplant patients are at a lower risk of CMV infection, in part owing to the lower burden of latent virus in renal allografts. The incidence of CMV infection in the renal transplant population is estimated to be between $8 \%$ and $32 \%(10,11)$. Serologic screening for antibodies to CMV should be performed in both donors and recipients before transplantation to identify patients who are at a risk of post-transplant infection and who might benefit from preventive strategies(12). Two strategies are commonly used for CMV infection prevention: (1) universal prophylaxis and (2) preemptive therapy. Universal prophylaxis involves giving antiviral therapy to all "at-risk" patients beginning at or immediately after transplantation for a defined time period. In preemptive therapy, patients are monitored at regular intervals for early evidence of CMV replication prior to the onset of clinical symptoms by using a laboratory assay(13). Patients with early replication are then treated with antiviral therapy to prevent symptomatic disease. Each approach has its advantages and disadvantages that must be considered in the context of the patient and the allograft(14). Preemptive therapy may decrease drug costs and toxicity. However, it requires excellent logistic coordination in order to obtain, receive, and act on results in a timely fashion; this can be difficult if patients live quite some distance from the transplant center. Prophylaxis might have the theoretical advantage of preventing reactivation of other viruses, such as human herpesvirus6 (HHV-6), and may be theoretically more likely to prevent the indirect effects of CMV infection. CMV resistance has been observed with both strategies. Drugs that have been evaluated for universal prophylaxis include acyclovir, ganciclovir, valacyclovir, valganciclovir, and immunoglobulin preparations. Based on current data, the optimal preemptive strategy is unknown. Preemptive therapy is well suited for transplant recipients at a low or intermediate risk of CMV disease, while prophylaxis may be better suited for those at a high risk $(15,16)$. Some studies have concluded that preemptive valganciclovir therapy and valacyclovir prophylaxis are equally effective in preventing CMV disease after renal transplantation and 
there is no difference in the overall costs between the two treatments $(17,18)$. The same conclusions were obtained in studies using ganciclovir as the antiviral drug(19). A meta-analysis of 32 trials (3737 patients) performed to compare the outcomes of various prophylactic antivirals in transplant patients at risk of CMV disease demonstrated that prophylaxis decreased CMV disease, CMV infection, and all-cause mortality(20). This meta-analysis showed that ganciclovir was more effective than acyclovir in preventing CMV disease. Valganciclovir and intravenous ganciclovir were found to be as effective as oral ganciclovir for prophylaxis. However, ganciclovir use may be associated with a greater rate of CMV resistance than valganciclovir use, at least in the highest-risk recipients $(21,22)$. The length of prophylactic treatment varies by institution but generally lasts for a minimum of 3 months.

Treatment of active CMV disease requires a combination of immunomodulation, antiviral therapy, and reduction of immunosuppression, if possible. The standard of care for treating CMV disease is 2 3 weeks of intravenous ganciclovir $(5 \mathrm{mg} / \mathrm{kg}$ twice daily, dose adjustments for renal dysfunction) with demonstration of clinical and virological responses to therapy. In contrast, oral ganciclovir should not be used to treat CMV disease because of the limited absorption and poor bioavailability. In seronegative patients and those with a slow response to therapy, the addition of CMV hyperimmune globulin (100 150 mg/kg per dose intravenously, administered monthly) may be useful(23). More recently, the introduction of valganciclovir has made possible the oral treatment of CMV disease in solid organ transplant recipients. In a trial of 21 renal transplant recipients who had symptomatic CMV disease and viremia and were treated with valganciclovir, all patients cleared their infection and none experienced relapse during a mean follow-up of 5.5 months(24). Recently, a multicenter randomized controlled trial of 321 solid organ transplant recipients demonstrated that oral valganciclovir was not inferior to intravenous ganciclovir in the initial treatment of CMV viremia(25). Indeed, valganciclovir was recently shown to be as effective as intravenous ganciclovir in the treatment of mild-to-moderate (i.e., nonsevere) CMV disease(26). The duration of treatment for CMV disease should be individualized and guided by virological and clinical surveillance. Viremia should be cleared before therapy is discontinued in order to reduce the risk of clinical relapse. Previous studies have shown that persistent viremia at the end of therapy is associated with a higher risk of disease relapse(27). Alternative therapies (not Food and Drug Administration-approved for use in solid organ transplant recipients) include the use of foscarnet, cidofovir, and leflunomide; these are reserved for treatment of antiviral resistance. Foscarnet is active against most ganciclovir-resistant strains of CMV but has neurotoxicity and renal toxicity with severe magnesium wasting. Cidofovir has been used in renal transplant recipients; however, it often induces nephrotoxicity. Both foscarnet and cidofovir may exhibit synergistic nephrotoxicity with calcineurin inhibitors(28). One of the biggest challenges regarding anti-CMV treatment is the emergence of antiviral resistance. Although this is more commonly noted in lung and pancreas transplant recipients, CMV resistance to ganciclovir has also been observed in renal transplant recipients. Ganciclovir resistance should be suspected when patients have persistent, unchanged viremia and/or symptoms at 2 weeks into therapy, and in such cases, genotypic assays for the detection of mutations associated with antiviral resistance should be performed. Treatment of resistant isolates may include the use of foscarnet with or without ganciclovir, or cidofo$\operatorname{vir}(29)$. Small case studies have demonstrated some efficacy of leflunomide for treating CMV disease in renal transplant patients. In a prospective study of $17 \mathrm{CMV}$-infected patients treated with leflunomide, $15(88 \%)$ showed viral clearance and healing of infected organs(27). Other potential therapeutic agents for multidrug-resistant CMV include immunoglobulins, leflunomide, and artesunate, although data supporting their use remain anecdotal(30-32). Hence, there is a need to identify novel agents and strategies for the management of CMV infection and disease.

\section{BK virus}

BK virus, a human polyomavirus, is a small DNA virus belonging to the human papovavirus family. The incidence of BK virus infection after organ transplantation is approximately $2.5 \%$, with onset usually within 1 year after transplantation(33-35). The kidney is the main site of latency. All immunosuppressive agents can induce BK virus 
reactivation. Clinical complications of BK virus infection include hemorrhagic cystitis, ureteral stenosis, and interstitial nephritis; these complications may lead to graft failure(36). Reduction/adjustment of immunosuppression remains the cornerstone in the treatment or prevention of BK nephropathy(37-40). Because the reconstitution of the immune system in the control of infection takes 4 to 12 weeks, it is imperative to start treatment as early as possible(41). The one risk encountered with immunosuppression reduction is the development of acute rejection. The preliminary results of Wali et al.(42) reflect the protocol used at the University of Maryland, which consists of intensive screening with subsequent stepwise decrease in immunosuppression. This protocol has resulted in clearance of viremia with no graft loss or significant rejection diagnosed. Specifically, immunosuppression reduction is as follows: step 1,50\% decrease in the mycophenolate mofetil (MMF) dose immediately after diagnosis; step 2, 50\% decrease in the target trough level of tacrolimus at 3 months if decoy cells persist; and step 3, elimination of MMF at 6 months if decoy cells persist. Maintenance dual therapy consists of the modified dose of tacrolimus and maintenance dose of prednisone (not exceeding 7.5 15 mg/week). In addition to decrease in immunosuppression, several centers have reported the use of several antipolyomaviral agents with anti-BK viral activity in vitro. These include cidofovir, leflunomide, quinolones, and intravenous immunoglobulin $(37,40,43)$.

\section{FUNGAL INFECTION}

\section{Candida species}

The incidence of candidal infection ranges from $5 \%$ to $50 \%$ in transplant recipients, depending on the type of organ transplant(44). Pancreas and liver transplant recipients withRoux-en-Y anastomosis have risk factors for candidal infection. Use of muromonab-CD3 monoclonal antibody and immunomodulatory viral infections including CMV and HHV-6 are also factors that increase the risk of invasive fungal infection(45).

Universal fluconazole prophylaxis remains a controversial strategy in the prevention of invasive fungal infection. Randomized trial demonstrated deduction in candidal colonization and superficial infection, but compared with oral nystatin, no difference in the incidence of invasive infections was found(46). Fluconazole prophylaxis is recommended only in high-risk patients, whereas oral nystatin or clotrimazole may be considered in low-risk patients(45).

Amphotericin B remains the drug of choice for candidal infections $(0.5 \sim 0.7 \mathrm{mg} / \mathrm{kg}$ per day). However, to avoid nephrotoxicity,less nephrotoxic lipid formulations may be considered in patients who can not tolerate conventional agents or in transplant recipients receiving calcineurin inhibitors. In addition, fluconazole use may be a reasonable treatment alternative for Candida albicans infection(47). Although $C$. albicansis the most common Candida species andissusceptible to fluconazole, the incidence of infections caused by other Candida species resistant to fluconazole is rising rapidly(48).

Caspofungin, the first echinocandin, has demonstrated activity against various Candida species(49). The combined use of cyclosporine and caspofungin may increase the overall exposure to caspofungin, thus increasing the risk of hepatotoxicity. On the other hand, early observations suggested that the concomitant use of caspofungin with tacrolimus led to decreased tacrolimus concentrations(49). Therefore, careful drug level monitoring is necessary.

\section{Aspergillus species}

Invasive aspergillosis is most commonly reported in lung and heart-lung transplant recipients and mostly occurs within 6 months after transplantation(45).

Amphotericin B is considered the first-line treatment for aspergillosis, but it may cause nephrotoxicity, particularly when the patient is receiving calcineurin inhibitors. Lipid formulations of amphotericin B are less likely to cause nephrotoxicity and can serve as substitutes, especially when chronic treatment is required for invasive aspergillosis(50). Itraconazole shows activity against Aspergillus species, but itraconazole mono therapy is associated with higher relapse rates than amphotericin Bmonotherapy. However, itraconazole can be used as step-down oral therapy(51). Voriconazole and caspofungin show activity against invasive aspergillosis and may be used to avoid amphotericin B nephrotoxicity(51). Coadministration of voriconazole and sirolimus is contraindicated and close monitoring of cyclosporine and tacrolimus levels is warranted when these azole-calci- 
neurin inhibitor combinations are used(52)

\section{Pneumocystis carinii}

Pneumocystis carinii pneumonia (PCP) is a common opportunistic infection in immunocompromised patients, including human immunodeficiency virus patients and transplant recipients. Although PCP prophylaxis is a routine practice, the drug regimen and therapy duration vary depending on the transplant center and type of organ transplanted(53). Trimethoprim-sulfamethoxazole provides excellent prophylaxis against PCP. Pentamidine (300 mg inhalation monthly) or dapsone (50 100 mg orally once daily) may also be used.

\section{OTHER INFECTIONS}

\section{Toxoplasmosis}

Toxoplasma gondii infection is of the greatest concern among heart transplant patients, but infection can occur in other types of transplant recipients, including kidney and liver recipients $(54,55)$. Toxoplasma organisms can remain encysted within muscle tissue, such as cardiac muscle. Thus, infection is acquired as a result of the reactivation of cysts that remain dormant in the donor hearts of toxoplasma-seronegative children. Clinical manifestations can occur as early as 2 weeks after transplantation. Manifestations include pneumonia, fever syndrome, myocarditis, chorioretinitis, and central nervous system disease. Current prophylaxis includes pyrimethamine/sulfadiazine for donor $(+) /$ recipient (-)patients. Trimethoprim-sulfamethoxazole is typically used in Recipient (+) patients. However, some experts also recommend trimethoprim-sulfamethoxazole for donor $(+) /$ recipient (-)patients. The duration of prophylaxis is usually 6 months.

\section{CONCLUSION}

The epidemiology of infections after solid organ transplantation has shifted as a result of changes in immunosuppressive strategies and improved survival. Immunosuppression must be linked with appropriate vaccinations, donor and recipient screening, patient education regarding infectious risks and lifestyle, monitoring, and antimicrobial prophylaxis. The risk of infections has increased with the use of lymphocyte-depleting agents. Some drugs that alter the mobilization of lymphocytes (e.g., FTY720, a high-affinity agonist of sphingosine 1-phosphate receptor-1) or other components of the inflammatory response may alter the histology of infection and further confound diagnosis. Thus, it should be anticipated that with the introduction of each new immunosuppressive agent, there could be unique effects on the presentation and epidemiology of infection in organ transplant recipients.

\section{REFERENCES}

1) West M, Pirenne J, Chavers B, Gillingham K, Sutherland DE, Dunn DL, et al. Clostridium difficile colitis after kidney and kidney-pancreas transplantation. Clin Transplant 1999;13:318-23.

2) Apaydin S, Altiparmak MR, Saribas S, Oztürk R. Prevalence of clostridium difficile toxin in kidney transplant recipients. Scand J Infect Dis 1998;30:542.

3) Batiuk TD, Bodziak KA, Goldman M. Infectious disease prophylaxis in renal transplant patients: a survey of US transplant centers. Clin Transplant 2002;16:1-8.

4) Blumberg HM, Burman WJ, Chaisson RE, Daley CL, Etkind SC, Friedman LN, et al. American Thoracic Society/Centers for Disease Control and Prevention/Infectious Diseases Society of America: treatment of tuberculosis. Am J Respir Crit Care Med 2003;167:603-62.

5) Hebert MF, Roberts JP, Prueksaritanont T, Benet LZ. Bioavailability of cyclosporine with concomitant rifampin administration is markedly less than predicted by hepatic enzyme induction. Clin Pharmacol Ther 1992;52:453-7.

6) Hebert MF, Fisher RM, Marsh CL, Dressler D, Bekersky I. Effects of rifampin on tacrolimus pharmacokinetics in healthy volunteers. J Clin Pharmacol 1999;39:91-6.

7) Naraqi S. Cytomegaloviruses. In: Belshe RB, ed. Textbook of human virology. 2nd ed. St. Louis: Mosby Year Book; 1991:889-924.

8) Brennan DC. Cytomegalovirus in renal transplantation. J Am Soc Nephrol 2001;12:848-55.

9) Mwintshi K, Brennan DC Prevention and management of cytomegalovirus infection in solid-organ transplantation. Expert Rev Anti Infect Ther 2007;5:295-304.

10) Patel R, Paya CV. Infections in solid-organ transplant recipients. Clin Microbiol Rev 1997;10:86-124.

11) Hartmann A, Sagedal S, Hjelmesaeth J The natural course of cytomegalovirus infection and disease in renal transplant 
recipients. Transplantation 2006;82(2 Suppl):S15-7.

12) Fischer SA, Avery RK; AST Infectious Disease Community of Practice. Screening of donor and recipient prior to solid organ transplantation. Am J Transplant 2009;9 Suppl 4:S7-18.

13) Cytomegalovirus. Am J Transplant 2004;4 Suppl 10:51-8.

14) Paya CV. Prevention of cytomegalovirus disease in recipients of solid-organ transplants. Clin Infect Dis 2001;32: 596-603.

15) Hodson EM, Craig JC, Strippoli GF, Webster AC. Antiviral medications for preventing cytomegalovirus disease in solid organ transplant recipients. Cochrane Database Syst Rev 2008;16:CD003774.

16) Benmarzouk-Hidalgo OJ, Cordero E, Martín-Peña A, García-Prado E, Gentil MA, Gomez-Bravo MA, et al. Prevention of cytomegalovirus disease using pre-emptive treatment after solid organ transplant in patients at high risk for cytomegalovirus infection. Antivir Ther 2009;14: 641-7.

17) Khoury JA, Storch GA, Bohl DL, Schuessler RM, Torrence SM, Lockwood M, et al. Prophylactic versus preemptive oral valganciclovir for the management of cytomegalovirus infection in adult renal transplant recipients. Am J Transplant 2006;6:2134-43.

18) Reischig T, Jindra P, Hes O, Svecová M, Klaboch J, Treska V. Valacyclovir prophylaxis versus preemptive valganciclovir therapy to prevent cytomegalovirus disease after renal transplantation. Am J Transplant 2008;8:69-77.

19) Small LN, Lau J, Snydman DR. Preventing post-organ transplantation cytomegalovirus disease with ganciclovir: a meta-analysis comparing prophylactic and preemptive therapies. Clin Infect Dis 2006;43:869-80.

20) Hodson EM, Jones CA, Webster AC, Strippoli GF, Barclay PG, Kable K, et al. Antiviral medications to prevent cytomegalovirus disease and early death in recipients of solid-organ transplants: a systematic review of randomised controlled trials. Lancet 2005;365:2105-15.

21) Paya C, Humar A, Dominguez E, Washburn K, Blumberg E, Alexander B, et al. Efficacy and safety of valganciclovir vs. oral ganciclovir for prevention of cytomegalovirus disease in solid organ transplant recipients. Am J Transplant 2004;4:611-20.

22) Boivin G, Goyette N, Gilbert C, Roberts N, Macey K, Paya $\mathrm{C}$, et al. Absence of cytomegalovirus-resistance mutations after valganciclovir prophylaxis, in a prospective multicenter study of solid-organ transplant recipients. J Infect Dis 2004;189:1615-8.

23) Tong CY, Bakran A, Williams H, Cheung CY, Peiris JS. Association of human herpesvirus 7 with cytomegalovirus disease in renal transplant recipients.. Transplantation 2000;70:213-6.

24) Babel N, Gabdrakhmanova L, Juergensen JS, Eibl N, Hoerstrup J, Hammer M, et al. Treatment of cytomegalovirus disease with valganciclovir in renal transplant recipients: a single center experience. Transplantation 2004;78:283-5.

25) Asberg A, Humar A, Rollag H, Jardine AG, Mouas H, Pescovitz MD, et al. Oral valganciclovir is noninferior to intravenous ganciclovir for the treatment of cytomegalovirus disease in solid organ transplant recipients. Am J Transplant 2007;7:2106-13.

26) Eid AJ, Razonable RR. New developments in the management of cytomegalovirus infection after solid organ transplantation. Drugs 2010;70:965-81.

27) John GT, Manivannan J, Chandy S, Peter S, Fleming DH, Chandy SJ, et al. A prospective evaluation of leflunomide therapy for cytomegalovirus disease in renal transplant recipients. Transplant Proc 2005;37:4303-5.

28) Kotton CN, Fishman JA. Viral infection in the renal transplant recipient. J Am Soc Nephrol 2005;16:1758-74.

29) Guidelines for vaccination of solid organ transplant candidates and recipients. Am J Transplant 2004;4 Suppl 10:160-3.

30) Battiwalla M, Paplham P, Almyroudis NG, McCarthy A, Abdelhalim A, Elefante A, et al. Leflunomide failure to control recurrent cytomegalovirus infection in the setting of renal failure after allogeneic stem cell transplantation. Transpl Infect Dis 2007;9:28-32.

31) Efferth T, Romero MR, Wolf DG, Stamminger T, Marin JJ, Marschall M. The antiviral activities of artemisinin and artesunate. Clin Infect Dis 2008;47:804-11.

32) Shapira MY, Resnick IB, Chou S, Neumann AU, Lurain NS, Stamminger T, et al. Artesunate as a potent antiviral agent in a patient with late drug-resistant cytomegalovirus infection after hematopoietic stem cell transplantation. Clin Infect Dis 2008;46:1455-7.

33) Smith SR, Butterly DW, Alexander BD, Greenberg A. Viral infections after renal transplantation. Am J Kidney Dis 2001;37:659-76.

34) Randhawa PS, Finkelstein S, Scantlebury V, Shapiro R, Vivas $\mathrm{C}$, Jordan $\mathrm{M}$, et al. Human polyoma virus-associated interstitial nephritis in the allograft kidney. Transplantation 1999;67:103-9.

35) Howell DN, Smith SR, Butterly DW, Klassen PS, Krigman HR, Burchette JL Jr, et al. Diagnosis and management of BK polyomavirus interstitial nephritis in renal transplant recipients. Transplantation 1999;68:1279-88.

36) Mylonakis E, Goes N, Rubin RH, Cosimi AB, Colvin RB, Fishman JA. BK virus in solid organ transplant recipients: 
an emerging syndrome. Transplantation 2001;72:1587-92.

37) Ramos E, Drachenberg CB, Wali R, Hirsch HH. The decade of polyomavirus BK-associated nephropathy: state of affairs. Transplantation. 2009;87:621-30.

38) Randhawa P, Ramos E. BK viral nephropathy: an overview. Transplant Rev 2007;21:77-85.

39) Hirsch HH, Knowles W, Dickenmann M, Passweg J, Klimkait T, Mihatsch MJ, et al. Prospective study of polyomavirus type BK replication and nephropathy in renal-transplant recipients. N Engl J Med 2002;347:488-96.

40) Hirsch HH, Brennan DC, Drachenberg CB, Ginevri F, Gordon J, Limaye AP, et al. Polyomavirus-associated nephropathy in renal transplantation: interdisciplinary analyses and recommendations. Transplantation 2005;79:1277-86.

41) Funk GA, Steiger J, Hirsch HH. Rapid dynamics of polyomavirus type BK in renal transplant recipients. J Infect Dis 2006;193:80-7.

42) Wali RK, Drachenberg C, Hirsch $H$. Intensive versus routine care screening for polyoma viral replication (cluster randomization) and a road map for stepwise modification of immunosuppression therapy. Am J Transplant 2008;8 Suppl 2:283.

43) Hilton R, Tong CY. Antiviral therapy for polyomavirusassociated nephropathy after renal transplantation. J Antimicrob Chemother 2008;62:855-9.

44) Villacian JS, Paya CV. Prevention of infections in solid organ transplant recipients. Transpl Infect Dis 1999;1:50-64.

45) Singh N. Fungal infections in the recipients of solid organ transplantation. Infect Dis Clin North Am 2003;17:113-34, viii.

46) Lumbreras C, Cuervas-Mons V, Jara P, del Palacio A, Turrión VS, Barrios C, et al. Randomized trial of fluconazole versus nystatin for the prophylaxis of Candida infection following liver transplantation. J Infect Dis 1996;174:583-8.

47) Rex JH, Bennett JE, Sugar AM, Pappas PG, van der Horst $\mathrm{CM}$, Edwards JE, et al. A randomized trial comparing fluconazole with amphotericin B for the treatment of candidemia in patients without neutropenia. Candidemia Study Group and the National Institute. N Engl J Med 1994;331:1325-30.

48) Rex JH, Pfaller MA, Galgiani JN, Bartlett MS, Espinel-Ingroff A, Ghannoum MA, et al. Development of interpretive breakpoints for antifungal susceptibility testing: conceptual framework and analysis of in vitro-in vivo correlation data for fluconazole, itraconazole, and candida infections. Subcommittee on Antifungal Susceptibility Testing of the National Committee for Clinical Laboratory Standards. Clin Infect Dis 1997;24:235-47.

49) Mora-Duarte J, Betts R, Rotstein C, Colombo AL, Thompson-Moya L, Smietana J, et al. Comparison of caspofungin and amphotericin B for invasive candidiasis. N Engl J Med 2002;347:2020-9.

50) Wingard JR, Kubilis P, Lee L, Yee G, White M, Walshe L, et al. Clinical significance of nephrotoxicity in patients treated with amphotericin B for suspected or proven aspergillosis. Clin Infect Dis 1999;29:1402-7.

51) Stevens DA, Kan VL, Judson MA, Morrison VA, Dummer S, Denning DW, et al. Practice guidelines for diseases caused by Aspergillus. Infectious Diseases Society of America. Clin Infect Dis 2000;30:696-709.

52) Outeda Macías M, Salvador P, Hurtado JL, Martín I. Tacrolimus-itraconazole interaction in a kidney transplant patient. Ann Pharmacother 2000;34:536.

53) Kasiske BL, Vazquez MA, Harmon WE, Brown RS, Danovitch GM, Gaston RS, et al. Recommendations for the outpatient surveillance of renal transplant recipients. American Society of Transplantation. J Am Soc Nephrol 2000;11 Suppl 15:S1-86.

54) Luft BJ, Naot Y, Araujo FG, Stinson EB, Remington JS. Primary and reactivated toxoplasma infection in patients with cardiac transplants. Clinical spectrum and problems in diagnosis in a defined population. Ann Intern Med 1983;99:27-31.

55) Michaels MG, Wald ER, Fricker FJ, del Nido PJ, Armitage J. Toxoplasmosis in pediatric recipients of heart transplants. Clin Infect Dis 1992;14:847-51. 